\title{
Quantitative prediction of strong motion for a potential earthquake fault
}

\author{
Aki K. $\left(^{*}\right)$, Bouchon M. $(*)$, Chouet B. $\left({ }^{*}\right)$, Das S. $\left({ }^{*}\right)$
}

Received on September 28 th, 1977.

Riassunto. - Questa nota descrive un nuovo metodo per calcolare le registrazioni accelerografiche per una data regione sismica in base alle leggi fisiche usando le informazioni relative alla tettonica ed alle proprietà fisiche della faglia sismica.

Il metodo si basa su di un nuovo modello sismico, chiamato "modello barriera ", caratterizzato da cinque parametri focali: lunghezza della faglia, larghezza, scorrimento massino, velocità di rottura ed intervallo di barriera. I primi tre parametri possono essere vincolati dalla tettonica a placche, il quarto parametro è approssimativamente una costante. Il parametro più importante, che controlla l'accelerazione del terremoto, è l'ultimo. l'intervallo «barriera".

$\mathrm{Vi}$ sono tre metodi per valutare l' «intervallo barriera" per una data regione sismica: 1) misurazione in superficie dello scorrimento attraverso fratture di faglia; 2) creazione di un modello che si adatti all'osservazione di campi vicini e lontani; 5 ) una legge che regoli $i$ dati per i piccoli terremoti nella regione.

Gli intervalli barriera sono stati valutati per una dozzina di terremoti e per quattro regioni sismiche, per mezzo dei tre metodi suindicati. I risultati preliminari ottenuti per la California suggeriscono che l'intervallo barriera possa essere determinato quando sia dato il massimo scorrimento. La relazione tra l'intervallo barriera ed il massimo scorrimento varia da una regione sismica all'altra. Ad esempio, l'intervallo appare insolitamente lungo per Kilanea (Hawaii), il che può spiegare perché traccia di forte scorrimento del terreno sia stata osservata soltanto nell'area epicentrale del terremoto delle Isole Hawaii del 29 novembre 1975.

SUMmaRY. - This paper describes a new method for calculating strong motion records for a given scismic region on the basis of the laws of physics

(*) Department of Earth and Planetary Sciences. Massachusetts Institute of Technology' 
using information on the tectonics and physical properties of the earthquake fault.

Our method is based on a earthquake model, called a "barrier model", which is characterized by five source parameters: fault length, width, maximum slip, rupture velocity, and barrier interval. The first three parameters may be constrained from plate tectonics, and the fourth parameter is roughly a constant. The most important parameter controlling the earthquake strong motion is the last parameter, "barrier interval".

There are three methods to estimate the barrier interval for a given seismic region: 1) surface measurement of slip across fault breaks, 2) model fitting with observed near and far-field seismograms, and 3) scaling law data for small earthquakes in the region. The barrier intervals were estimated for a dozen earthquakes and four seismic regions by the above three methods. Our preliminary results for California suggest that the barrier interval may be determined if the maximum slip is given. The relation between the barrier interval and maximum slip varies from one seismic region to another. For example, the interval appears to be unusually long for Kilauea, Hawaii, which may explain why only scattered evidence of strong ground shaking was observed in the epicentral area of the Island of Hawaii earthquake of November 29. 1975.

The stress drop associated with an individual fault segment estimated from the barrier interval and maximum slip lies between 100 and 1000 bars. These values are about one order of magnitude greater than those estimated earlier by the use of crack models without barriers. Thus, the barrier model can resolve, at least partially, the well known discrepancy between the stress-drops measured in the laboratory and those estimated for earthquakes.

\section{INTRODUCTION.}

We are interested in predicting earthquake strong motion on the basis of the laws of physics using information on the tectonics and physical properties of the earthquake fault which can be measured at the present time. Recent advances in the study of earthquake source mechanisms, plate tectonics, rok mechanics, and approach viable and gation in realistic media have made this new approach viable and promising to supplement the conventional approach based entirely on the past records of strong motion and earthquake statistics.

The first successful attempt of theoretical prediction of strong motion was made by Aki (1968) and Haskell (1969) for the station no. 2 record of the Parkfield earthquake of 1966. The earthquake model used by them was a propagating dislocation parametrized by fault length, fault width, rupture velocity, final uniform slip, and rise time. Among these five parameters, the first four can be determined relatively 
easily from various seismological data and their reliable estimates have been obtained for many earhquakes. The results from plate tectonics also gave constraints on these parameters.

For the prediction of strong motion, however, the most important parameter is the rise time which controls the high frequency end of seismic spectra. Because of difficulties in separating source and path effects on short period waves, the determination of this parameter has been made for only a few earthquakes.

To resolve this problem, we have taken two approaches: spectral analysis of small earthquakes and theoretical work on rupture propagation. In the spectral analysis work, we used the coda method developed by Aki and Chouet (1975) for separating the source, attenuation, and scattering effects on short period waves. The main purpose of the work was to find the scaling law of seismic spectrum which describes how the seismic spectrum grows with earthquake magnitude.

The other approach was to find the fault slip as a function of time and location on the fault for given conditions of tectonic stress, material strength on the fault, and the fracture criterion. The results of such work will not only give us the physical meaning of "rise time ", but also allow us to relate the physical properties of an earthquake fault with seismic motions generated from the fault. Thus, Das and Aki (1977) arrived at a new versatile earthquake model called the «barrier model ». In this model, the ad-hoc parameter « rise time » is replaced by a more physical parameter, "barrier interval». The new model allows us to estimate the barrier interval from the observed seismogram of an earthquake, from the scaling law of seismic spectrum for small earthquakes in a seismic zone, and from the direct measurement of fault breaks along an earthquake fault.

We have estimated the barrier interval for six earthquakes by direct measurement of the fault slip, for an additional six earthquakes by model fitting with observed seismograms, and for four seismic areas from locally observed scaling laws of seismic spectra. The results suggest that the barrier interval may be reliably determined by knowing the expected maximum slip. On the other hand, the expected maximum slip, fault length, and width are constrained by plate tectonics and the rupture velocity is usually within the range of 2 to $3 \mathrm{~km} / \mathrm{sec}$. Thus, our barrier model can give all the necessary parameters for calculating strong motion by the laws of physics. An interesting and important aspect of this model is that the tectonic stress is implicitly contained in 
the maximum slip vs, barrier interval relation but is not an explicitly required parameter for calculating strong motion.

In the present paper, we shall first review how the idea of the "barrier interval » has evolved from the analysis of the growth of source spectrum with magnitude. Then, we shall discuss the results of numerical calculation of rupture propagation over a fault plane with distributed barriers. We shall show how the barrier model determined seismologically compares with the surface measurements of fault breaks for the San Andreas fault. We shall then obtain the barrier interval for many earthquakes and several seismic areas by comparing synthetic seismograms with cbserved data, and by direct measurements of fault slip. The results will be summarized in a diagram showing barrier interval as a function of maximum slip.

\section{OBSERVED SCALING LAW OF SEISMiC SPECTRUM FOR SMALL EARTH- QUAKES.}

The manner in which the seismic spectrum grows with earthquake magnitude is called the "scaling law ». A simple scaling law based on the assumption that large and small earthquakes are similar has explained fairly well observations of earthquakes with magnitudes $M$ greater than 6 (Aki, 1967, 1972). The similarity assumption implies the constancy of stress drop independent of magnitude which is supported by observations, at least for shallow earthquakes with $M>6$ (Kanamori and Anderson, 1975). The validity of the similarity assumption means that there is no unique physical length involved in earthquake phenomena except the total fault length.

Using the coda method developed by Aki and Chouet (1975), we have studied the scaling law for small earthquakes in Tsukuba and Oishiyama, Japan, Stone Canyon and San Fernando, California, and Kilauea, Hawaii. As described in Chouet et al. (1978), except for Hawaii, all of the areas showed some departure from what would be expected under the similarity assumption. For example, if the similarity assumption is valid, the relation between corner frequency and seismic moment must be a straight line in the log-log plot with a slope of -3 . Except for Hawaii, the loci of corner frequency follow zig-zag paths consisting of segments of two distinct types. One is a vertical path 
with constant corner frequency and the other is an inclined line with a slope of -3 .

A similar zig-zag path was found by Street et al. (1975) for earthquakes in the central United States.

Violation of simple similarity assumption was also observed by Tsujiura (1978) for the Kanto region, Japan, and by Rautian and Khalturin (1976) for Garm region, USSR, using the coda method.

Let us now examine closely the results from Stone Canyon, California, to find a clue for the physical meaning of the observed scaling laws. Reproduced from Chouet et al (1978), Fig. 1 shows the average source spectra for various magnitudes and Fig. 2 compares the corner frequency with those obtained for earthquakes in the same area but by various methods based on deterministic models. Since our method relies on coda waves, for which the path effect and the effect of azimuthal radiation is presumably average out, we expect our estimate of corner frequency to be more stable. In fact, the points obtained by other methods scatter around the curve obtained by the coda method. In particular, the very weak dependence of corner frequency (near $1 \mathrm{~Hz}$ ) on magnitude observed by Johnson and Mc Evilly (1974) is supported by our results. While the corner frequency is nearly constant at $1 \mathrm{~Hz}$ the spectral shape changes with magnitude as shown in Fig. 1. The high frequency asymptote shows a steeper slope for $M=5$ than for $M=4$. We shall find that all these observations can be explained by considering rupture propagation along a fault plane with distributed barriers. 


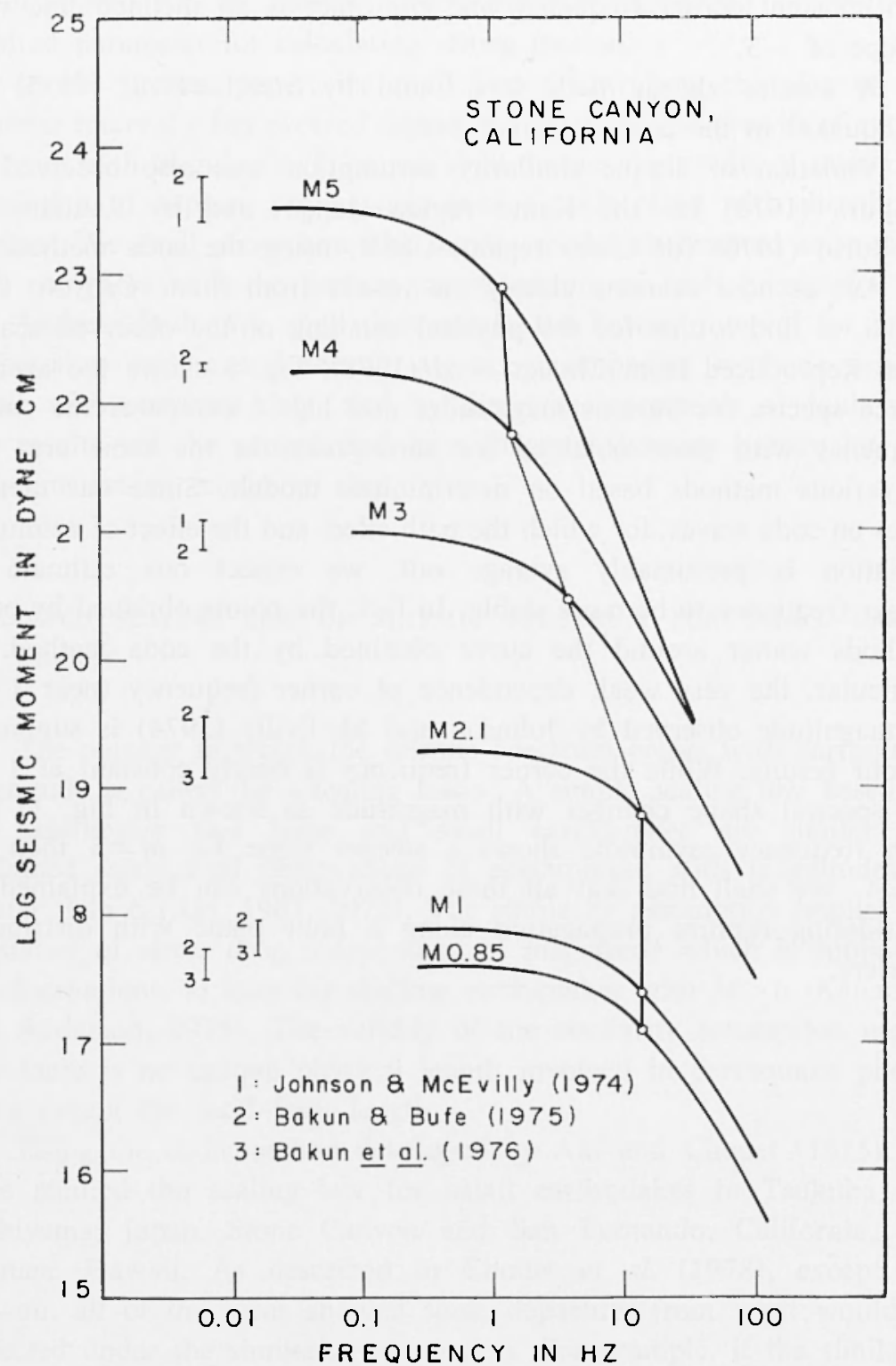

Fig. 1. Growth of the seismic source spectrum with magnitude for earthquakes in the San Andreas rilt zone near Stone Canyon, central California. The locus of corner frequencies appears to consist of three distinct segments between magnitudes $1(\mathrm{M} \mathrm{I})$ and 5 (M 5). Reproduced from Chouet et al., (1978). 


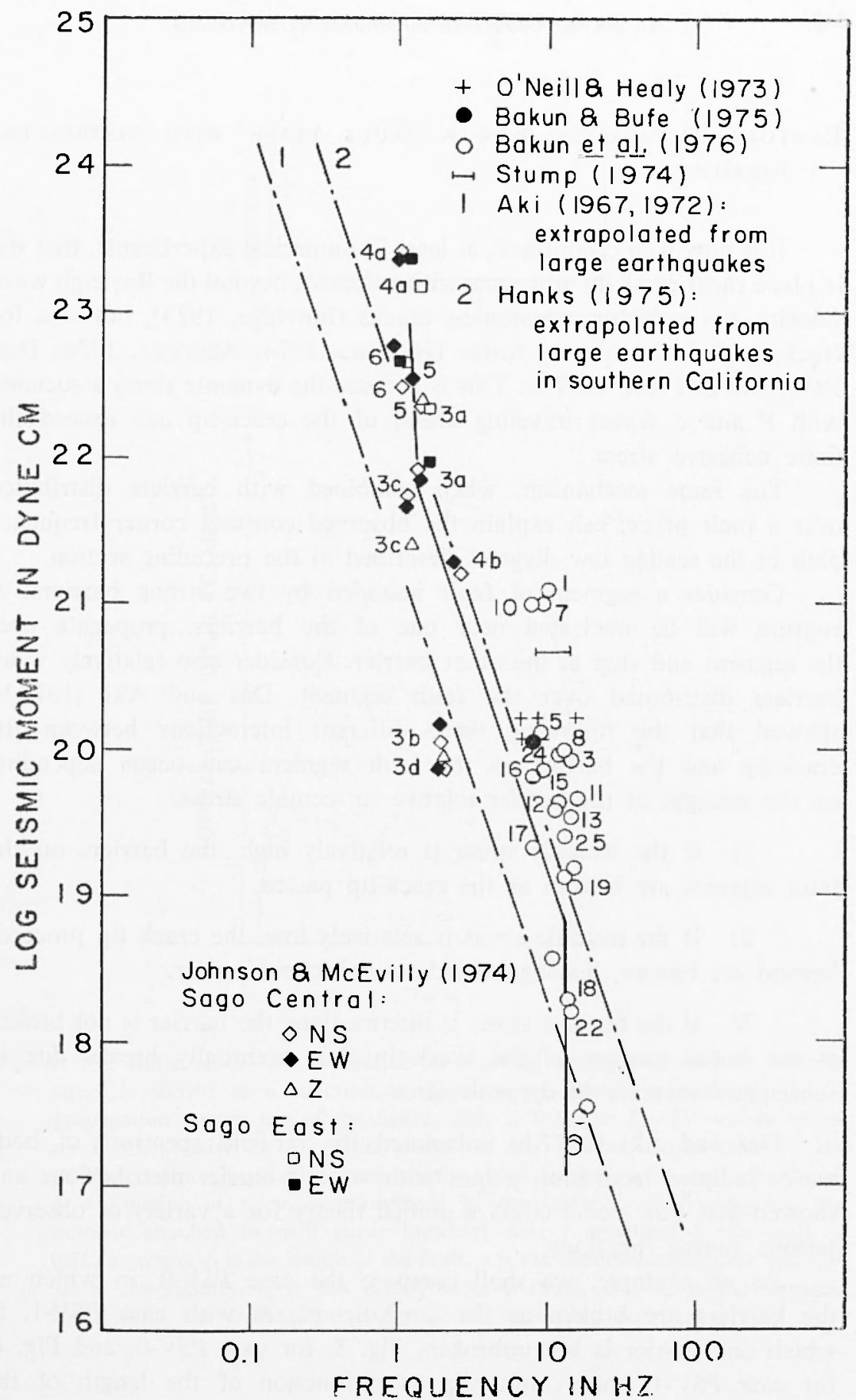

Fig. 2. Comparison of the corner-frequency vs. moment relation determined by the coda method (solid line), various deterministic methods (for individual earthquakes) and extrapolation from larger earthquakes (dashed lines). Reproduced from Chouet et al., (1978). 


\section{Rupture propagation over a Fault plane with distributed BARRIERS.}

It is now well established, at least in numerical experiments, that the in plane shear crack an propagate with velocities beyond the Rayleigh wave velocity, not only for cohesionless cracks (Burridge, 1973), but also for cracks with finite cohesive forces (Hamano, 1974; Andrews, 1976; Das, 1976; Das and Aki, 1977 a). This is because the dynamic stress associated with $P$ and $S$ waves traveling ahead of the crack-tip can exceed the finite cohesive stress.

The same mechanism, when combined with barriers distributed over a fault plane, can explain the observed constant corner frequency path in the scaling law diagram described in the preceding section.

Consider a segment of fault bounded by two strong barriers. A rupture will be nucleated near one of the barriers, propagate over the segment and stop at the other barrier. Consider also relatively weak barriers distributed over the fault segment. Das and Aki (1977 b) showed that the following three different interactions between the crack-tip and the barrier on the fault segment can occur depending on the strength of the barrier relative to tectonic stress.

1) If the tectonic stress is relatively high, the barriers on the fault segment are broken as the crack-tip passes.

2) If the tectonic stress is relatively low, the crack tip proceeds beyond the barrier, leaving behind an unbroken barrier.

3) If the tectonic stress is intermediate, the barrier is not broken at the initial passage of the crack-tip; but eventually breaks due to subsequent increase in dynamic stress.

Das and Aki (1977 b) calculated the far-field spectrum of body waves radiated from fault planes with various barrier distributions and showed that this model offers a unified theory for a variety of observed seismic source functions.

As an example, we shall compare the case PSV-0, in which all the barriers are broken as the crack-tip passes with case $P S V-1$, in which one barrier is left unbroken. Fig. 3, for case PSV-0, and Fig. 4, for case $P S V^{\prime}-1$, show fault slip as a function of the length of the 

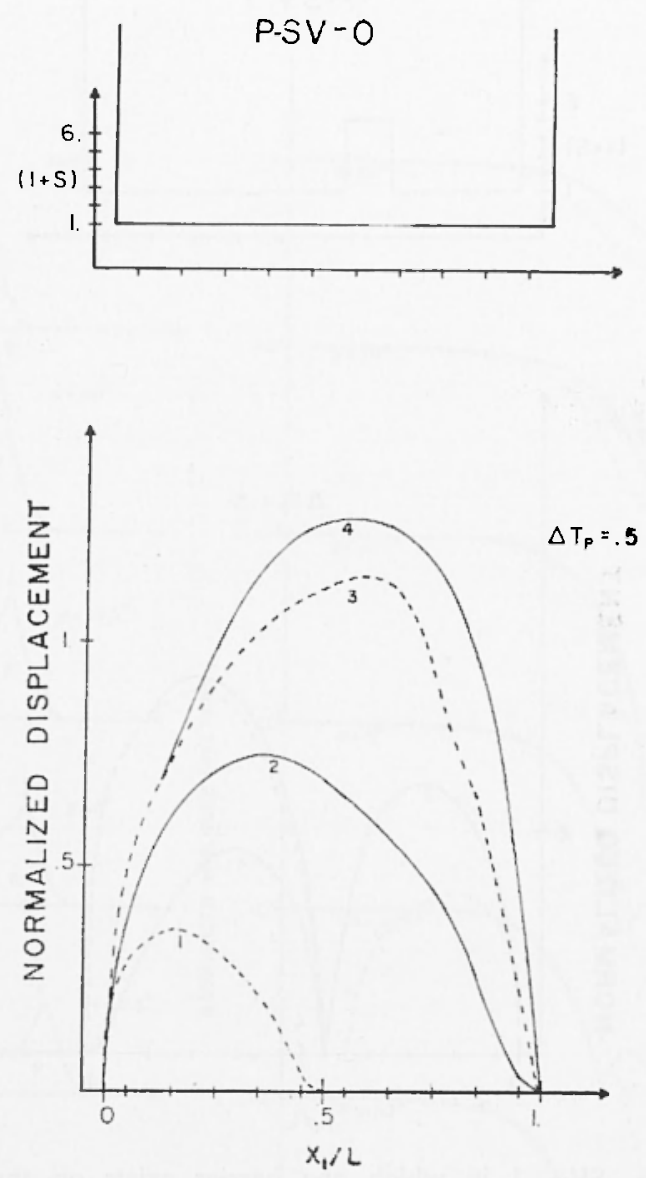

Fig. 3. The value of $(1+S)$, a measure of material strength relative to tectonic stress is shown as a function of distance, $x_{1}$, along the path of rupture propagation on the top of the figure. This is the case $P-S V-0$ in which no barriers exist on the fault plane. At the bottom, snap shots of the parallel component displacement on the crack surface $u_{1}\left(x_{1}, o, t\right)$ are shown as a function of $x_{1}, u_{1}$ is normalized by the factor $L\left(\tau_{0}-\tau_{f}\right) / \mu$ and the number attached to each curve indicates time $l$ measured in the unit of $0.5 L / \alpha$, where $L$ is the length of the fault, $\alpha$ is the compressional wave velocity, $\mu$ is the rigidity, $\tau_{0}$ is the initial tectonic stress, and $\tau_{f}$ is the dynamic function of the fault plane. Reproduced from Das and Aki (1977). 

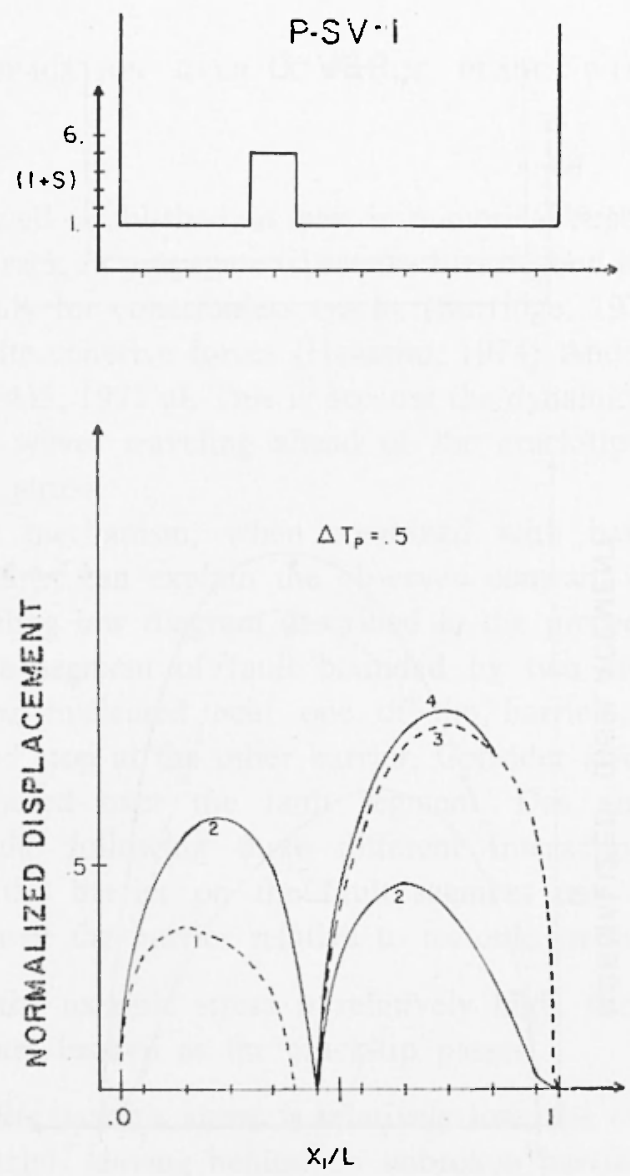

Fig. 4. Case $P-S V-1$ in which one barrier exists on the fault plane. See Fig. 3 legend for details. The crack tip skips the barrier without breaking it. Reproduced from Das and Aki (1977).

fault at several time intervals. The wave-forms of the body waves radiated in case PSV-1 are shown in Fig. 5 tcgether with the spectral density (solid line). The dashed lines in Fig. 5 show the shape of spectral density for case PSV-0. The corner frequency is nearly the same for both cases $P S V-0$ and $P S V-1$, but the high-frequency content relative to the low frequency is greater for case PSV-1 than for case $P S V$-0. Since the average slip over the fault plane is smaller for case $P S V-1$ than for case PSV-0, the seismic moment is also smaller. Thus 
UNILATERAL INPLANE SHEAR CRACK

P.SV -I
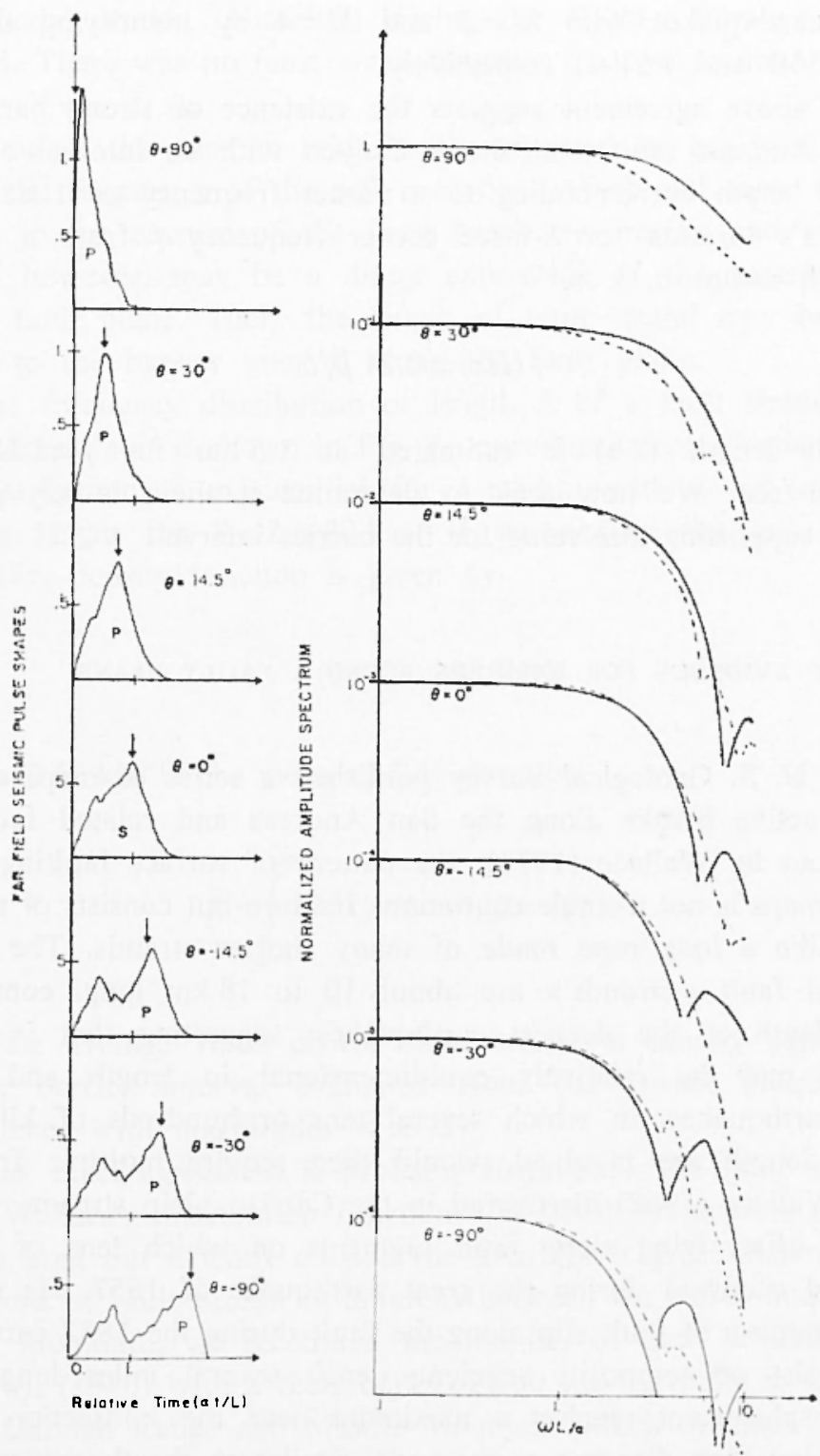

Fig. 5. The far-field wave form is shown for $P$ waves for various azımuths on the left for case $P-S V-1$. The arrows indicates the arrival of the stopping phase from the moving crack tip. The absolute value of the Fourier transform of the far-field wave form is shown on the right in a logarithmic scale normalized to the value at zero frequency. For comparison, the dashed lines on the Figure of the spectrum show the curves for case $P-S V-0$. Reproduced from Das and Aki (1977). 
we can explain all of the observations described earlier for the Stone Canyon earthquakes with $M=5$ and $M=4$ by identifying them as cases $P S V-0$ and $P S V-1$, respectively.

The above agreement suggests the existence of strong barriers in the San Andreas fault near Stone Canyon with an interval equal to the fault length corresponding to a corner frequency of $1 \mathrm{~Hz}$. Using Madariaga's formula for $S$-wave corner frequency $f$ from a circular fault with radius $a$, i. e.

$$
f(H z)=0.21 \beta / a
$$

the fault length (2a) is estimated at $1.5 \mathrm{~km}$ for $f=1 \mathrm{~Hz}$ and $\beta=3.5 \mathrm{~km} / \mathrm{sec}$. We now seek to determine if there is any geologic evidence supporting this value for the barrier interval.

\section{Geologic evidence for barriers along a fault plane.}

The U. S. Geological Survey published a series of maps showing recently active breaks along the San Andreas and related faults. As pointed out by Wallace (1973), the pattern of surface faulting shown in these maps is not a single continuous fracture but consists of multiple breaks, like a long rope made of many shorter strands. The longest individual fault "strands" are about 10 to $18 \mathrm{~km}$ long, comparable to the depth of the deepest earthquakes, suggesting that individual fractures may be relatively equidimensional in length and depth. Larger earthquakes, in which several tens or hundreds of kilometers of fault length are involved, would then require multiple fractures. Earlier Wallace (1968) discovered in the Carrizo plain streams with no apparent offset lying along fault segments on which tens of feet of offset had occurred during the great earthquake of 1857 . He suggests that the pattern of fault slip along the fault during the 1857 earthquake may consist of composite segments, each several miles long, along which displacement reaches a maximum near the midsection of the segment and then dies out at the ends, similar to the theoretical curve shown in Fig. 4, for the case of $P S V-1$. A similar observation has been made for other earthquakes. One of the most impressive examples is shown in Fig. 6, reproduced from Tchalenko and Berberian (1975). 
Fig. 6 shows the pattern of fault slip in the bedrock section (Khidbas) and alluvial section (Nimbluk) during the Dasht-e Bayaz earthquake of 1968. There was no fault break between the two sections for about $4 \mathrm{~km}$.

Some of the gaps in fault breaks reported by geologists may be due to the properties of the soil near the surface and some may even be due to the erasure of the fault break by erosion and vegetation. Others, however, may be a direct expression of the pattern of slip on the fault plane. Then, the length of fault strand may be directly related to the barrier interval along the fault plane.

The frequency distribution of length $L$ of a fault strand for the San Andreas fault is shown in Fig. 7, reproduced from Wallace (1973). The distribution is exponential for $L<8 \mathrm{~km}$ with a tail of roughly uniform height for $8<L<20 \mathrm{~km}$. If we neglect the tail part, the probability density function is given by

$$
f(L) d L=\beta e^{-\beta L} d L
$$

with $\beta=0.66 \mathrm{~km}^{-1}$. The mean of $L$ is given by

$$
\bar{L}=\int_{0}^{\infty} L f(L) d L=1 / \beta=1.5 \mathrm{~km}
$$

Thus, the average value of the fault strand is exactly equal to the average barrier interval estimated from the corner frequency for earthquakes with magnitudes 4 to 5 .

This exact agreement is probably fortuitous. The fault zone from which Wallace's distribution function was obtained includes our Stone Canyon area but extends outside the area for a great distance. Since the nature of fault breaks is different between the north and south of Middle Mountain, we recounted the number of fault strands mapped by Brown (1970) with a scale of 1: 62,500 for the fault zone between North Gabilan Range and Middle Mountain which includes our Stone Canyon area. Table I shows the number of fault segments with a given range of length. The numbers in brackets are obtained if we exclude branches of the main fault. 


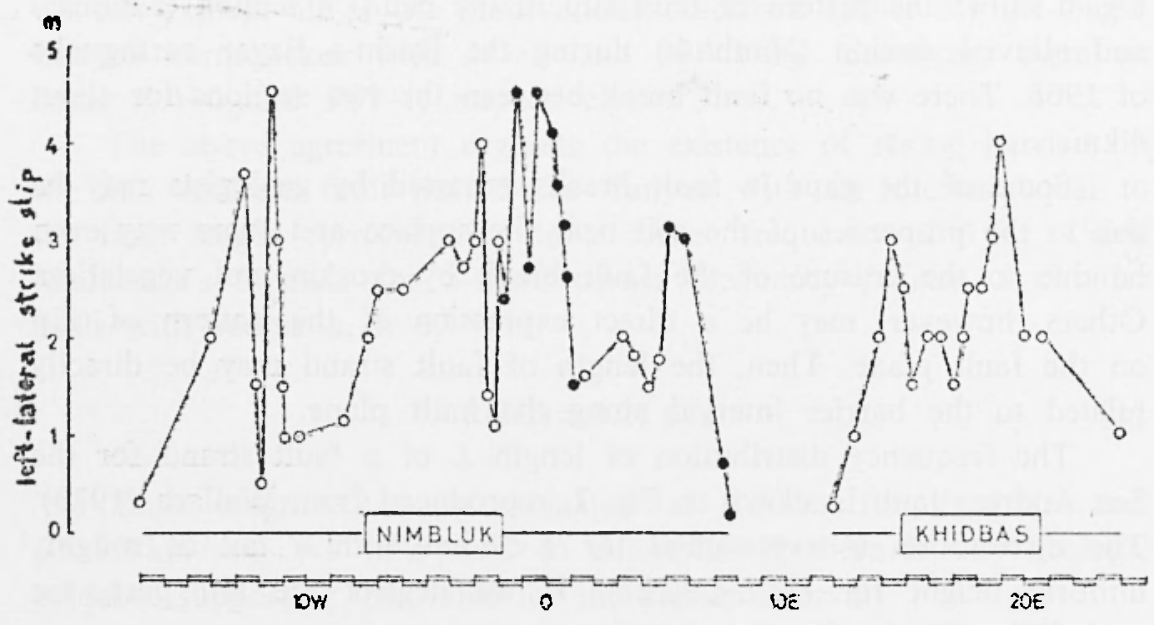

Fig. 6. Horizontal displacement along the fault of Dasht-e Bayaz earthquake of 1968. Vertical axis is left-lateral displacement in meters. Horizontal axis is distance along the fault in kilometers. Solid circles indicate north-facing scarp and open circles south-facing scarp. Note the gap near 10 E. Reproduced from Tchalenko and Berberian (1975).

TABLE I

\begin{tabular}{lccccccccccccc}
\hline Range in length & $0 \sim 1$ & $1 \sim 2$ & $2 \sim 3$ & $3 \sim 4$ & $4 \sim 5$ & $5 \sim 6$ & $6 \sim 7$ & $7 \sim 8$ & $8 \sim 9$ & $9 \sim 10$ & $10 \sim 11$ \\
Frequency & 12 & 11 & 5 & 2 & 8 & 2 & 2 & 2 & 1 & 1 & 1 \\
& $(5)$ & $(5)$ & & & & & & & & & \\
\end{tabular}

Nevertheless, we find a certain average value on a map of given exclude them.

The above average length of fault segments depends on the scale of map used for mapping. Obviously, on the scale of, say, 1:10,000,000, these segments will merge into a continuous line. On the other hand, the average length may become much shorter on the scale of, say, 1: 10,000.

Nevertheless, we find a certain average value on a map of given scale, although if we look at the whole range from grain size of minerals to the length of the entire San Andreas fault, there is no physically meaningful average length of fault segments. This situation is similar to the existence of constant corner frequency for a certain range of earthquake magnitudes mentioned earlier. 


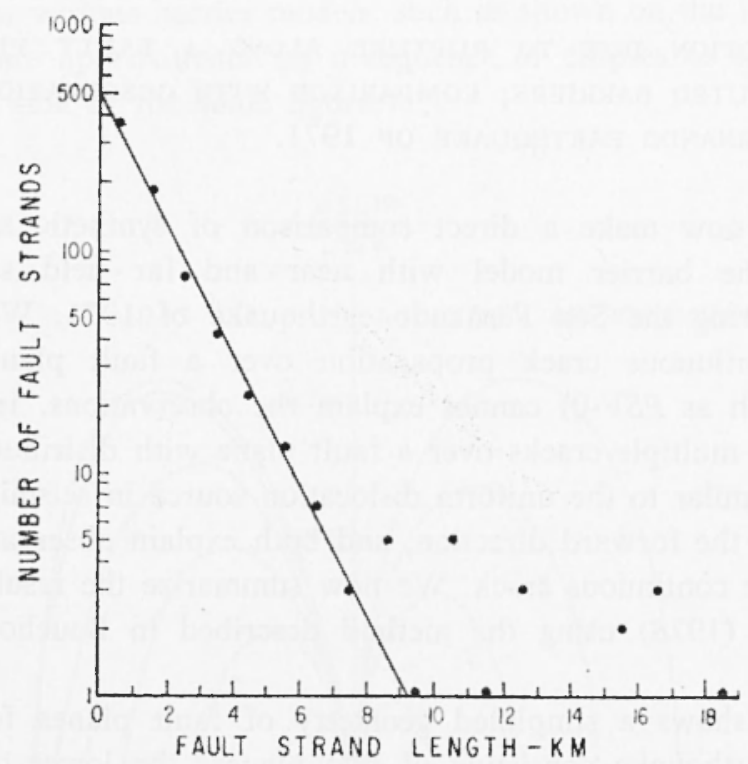

Fig. 7. Frequency distribution of the length of fault strands along the San Andreas fault. Reproduced from Wallace (1973).

If we look at the whole range of earthquake source size, which covers from a few meters to a thousand kilometers, there is no physically meaningful average source size. The observed constant corner frequency, however, suggests the existence of a physical condition which has a characteristic average length and controls the occurrence of earthquakes in a certain magnitude range. The same physical condition may also control the length of fault breaks observed on the surface. We propose to call this length «barrier interval ».

The observed fault breaks along the San Andreas fault from North Gabilan Range to Middle Mountain show an average barrier interval of 3 to $4 \mathrm{~km}$. On the other hand, the corner frequency for earthquakes with $4<M<5$, when interpreted by a model of a circular crack, suggests $1.5 \mathrm{~km}$.

As discussed later, the barrier interval may not be a constant of a fault zone but vary with the amount of slip and other parameters of the earthquake process. 
SEISMIC MOTION DUE TO RUPTURE Along a FAUlt Plane With DISTRIBUTED BARRIERS; COMPARISON WITH OBSERVATIONS OF THE San Fernando earthouake of 1971.

Let us now make a direct comparison of synthetic seismograms based on the barrier model with near-and far-field seismograms observed during the San Fernando earthquake of 1971. We find that a single continuous crack propagation over a fault plane with no barriers (such as PSV-0) cannot explain the observations. Interestingly, we find that multiple cracks over a fault plane with distributed barriers is roughly similar to the uniform dislocation source in seismic radiation, especially in the forward direction, and both explain observations better than a single continuous crack. We now summarize the results obtained by Bouchon (1978) using the method described in Bouchon and Aki (1977).

Fig. 8 shows a simplified geometry of fault planes for the San Fernando earthquake consisting of two planes; the lower one dipping at an angle of about $52^{\circ}$, and the upper one at a lower angle. The rupture originated at a depth of 12 to $14 \mathrm{~km}$ and propagated upwards until it broke the free surface. The slip-functions obtained by Das and Aki

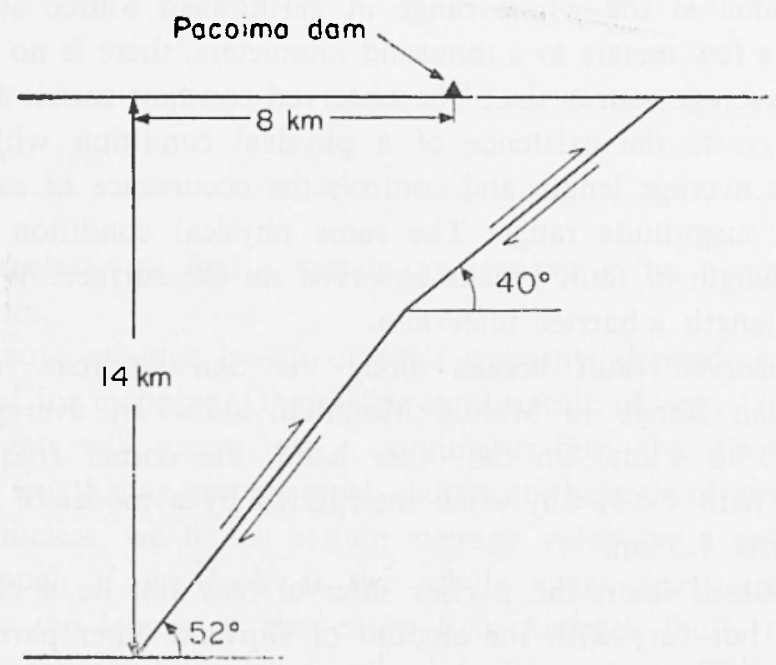

Fig. 8. Fault-plane geometry used to model the San Fcrnando earthquake of 1971 and the site of the strong motion seismograph at Pacoima Dam. Reproduced Irom Bouchon (1977). 
( 1977 b) for various barrier models, such as shown on the left hand side of Fig. 9, are approximated by a sequence of ellipses as shown on the right hand side of the same figure.

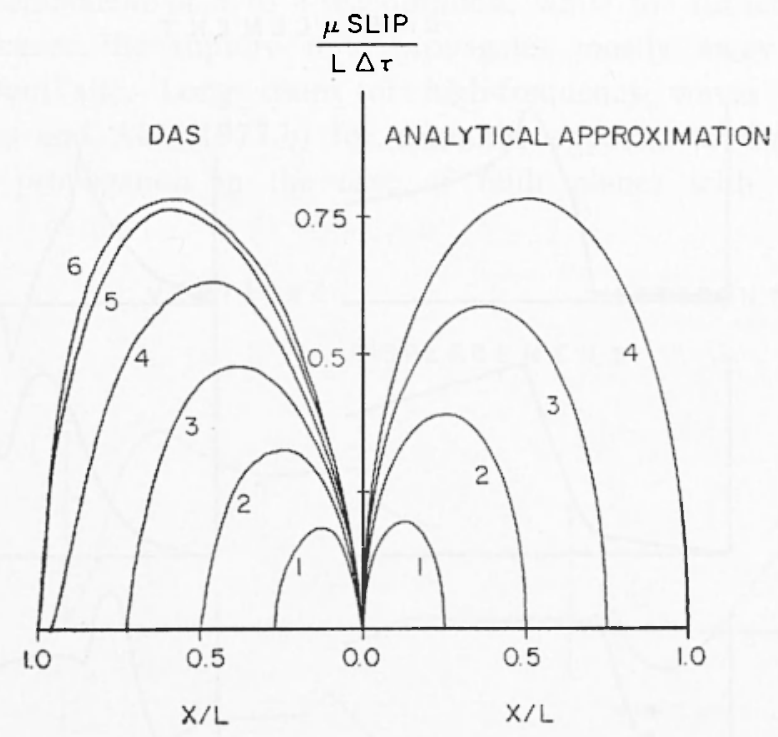

Fig. 9. Slip functions obtained as a numerical solution of a crack problem on the left and those approximated by a sequence of ellipses used in calculating the synthetic seismogram at Pacoima at Dam. Reproduced from Bouchon (1978).

Fig. 10 shows the synthetic surface ground displacement records at the Pacoima Dam due to slip on the lower segment of the fault. These four records are computed for different slip functions. From the top to the botton, they are a uniform step-dislocation, a single continuous unilateral crack nucleating at the bottom, a single continuous bilateral crack nucleating at the center of the lower fault segment, and multiple cracks with ten equidistant unbroken barriers nucleated at the bottom and propagated in the manner similar to the one obtained for the case PSV-1 by Das and Aki. The results for the uniform dislocation and the multiple crack slip functions are remarkably similar. They both show a sharp change in slope at the arrival of the shear waves from the nucleation point. Such sharp arrivals were recorded by a strons motion seismograph at Pacoima Dam. On the other hand, single 
continuous cracks cannot generate these sharp $S$ arrivals in contradiction to cbservation.

DISPLACEMEN T

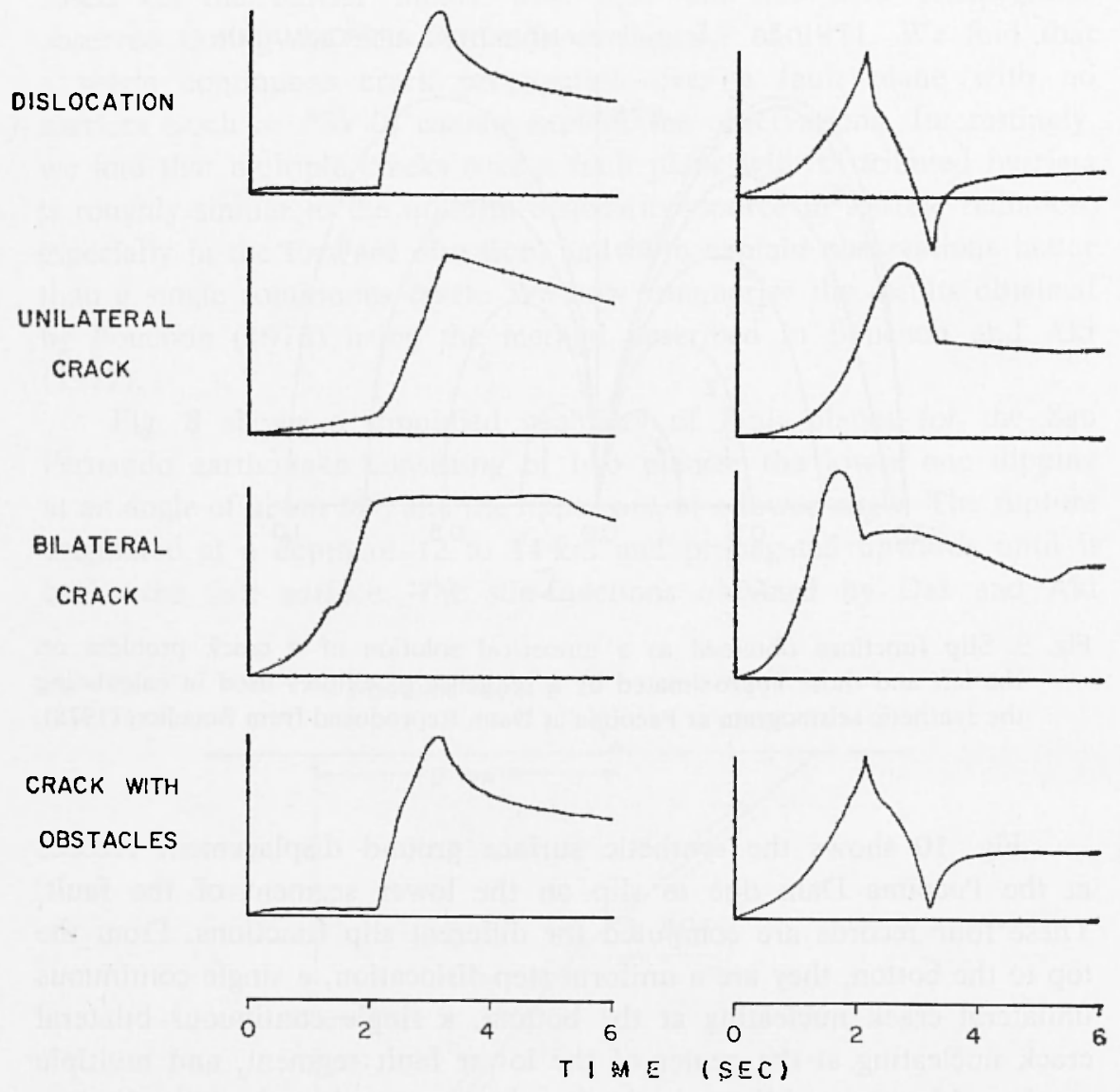

Fig. 10. Synthetic surface ground motion at Pacoima Dam due to slip on the lower segment fault. The top trace corresponds to the case of uniform step-dislocation, the second from the top to the case of a single continuous unilateral crack nucleating at the bottom, the third to the case of a single continuous bilateral crack nucleating at the center of the lower fault segment, and the bottom trace to the case of multple cracks with ten equidistant unbroken barriers nucleated at the bottom. Reproduced from Bouchon (1978). 
The synthetic ground displacement due to slip on the upper segment of the fault is shown in Fig. 11. For this segment, we find a striking difference between the uniform dislocation and the multiple cracks with seven unbroken barriers. The latter produces a large highfrequency component of 3 to $4 \mathrm{sec}$ duration, while the forner does not. This is because the rupture now propagates mostly away from the Pacoima Dam site. Long trains of high-frequency waves are noted also by Das and Aki (1977 b) for azimuths opposite to the direction of rupture propagation in the case of fault planes with distributed barriers.

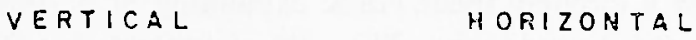

DISPLACEMENT

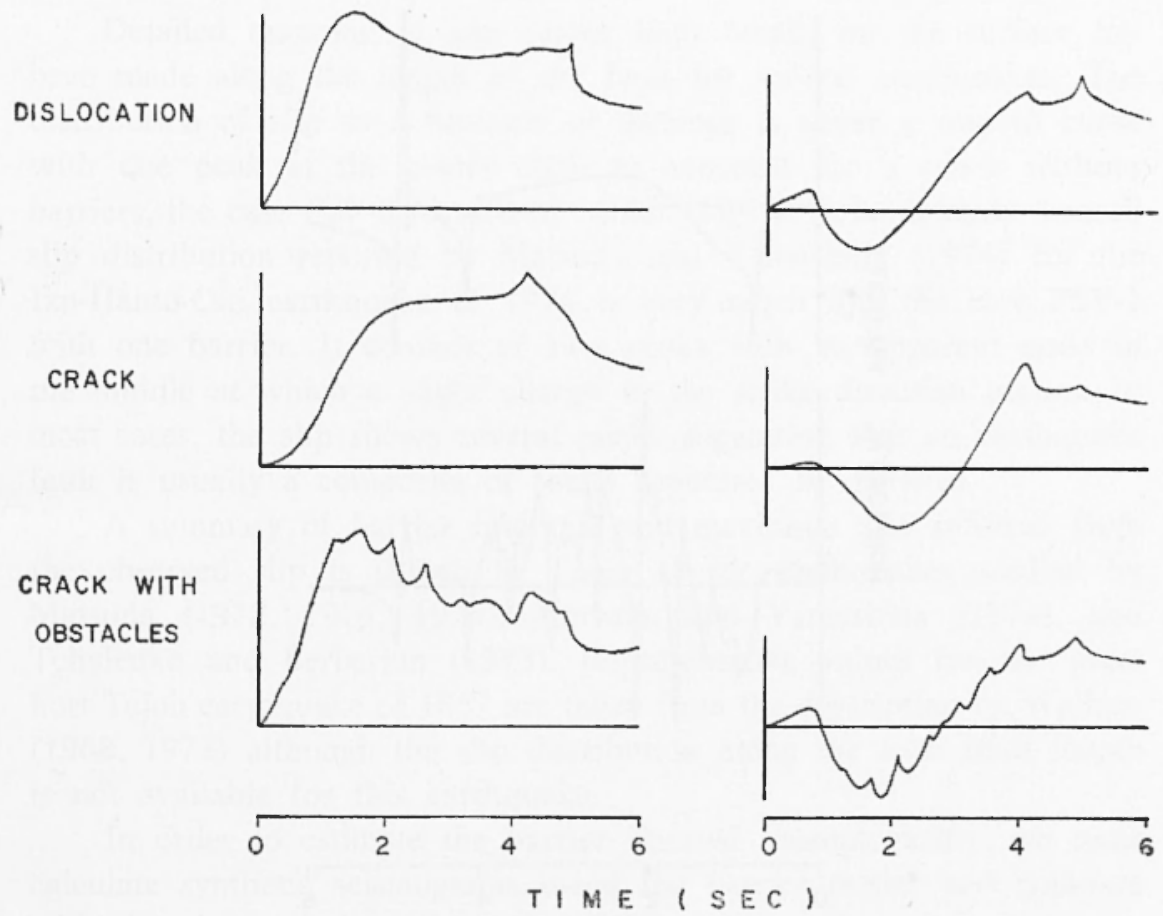

Fig. 11. Synthetic surface motion at Pacoima Dam due to slip on the upper segment of the fault. The top trace corresponds to the case of uniform step-dislocation, the second to the case of a unilateral single crack nucleating at the bottom of the upper fault segment, and the bottom trace to the case of multiple cracks with seven unbroken barriers. 
Fig. 12 shows synthetic horizontal particle velocities at the Pacoima Dam obtained from the displacement due to the faulting of the upper segment; uniform dislocation at the tcp and multiple cracks at the bottom. The last sharp arrival is the Rayleigh wave from the point of surface break. The model of multiple cracks explains well the major features of the Pacoima Dam records.

The methods used for calculating synthetic seismograms at the Pacoima Dam are restricted to two-dimensions. We need a threedimensional model for comparison with teleseismic $P$ wave data. For this purpose we assumed that the initial crack of the multiple crack model is a circular shear crack expanding at a rupture velocity of $0.9 \beta$ and stopping suddenly. The slip function for this crack has been calculated by Madariaga (1976). Bouchon (1978) again uses an analytic

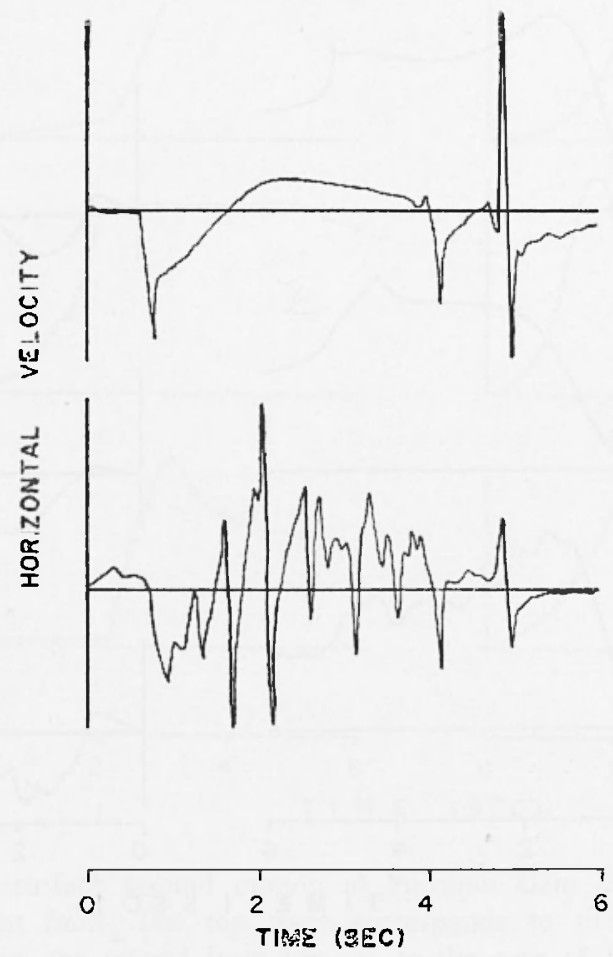

Fig. 12. Synthetic horrzuntal particle velocities at Pacoima Dam obtained from the displacements shown in Fig. 11. The upper trace corresponds to the case of uniform dislocation and the lower trace to the case of multiple cracks. Reproduced from Bouchon (1978). 
approximation of Madariaga's solution. Synthetic $P$ wave forms are computed for a circular crack buried at the hypocenter in a half-space. The effects of geometrical spreading, reflection losses, mantle attenuation, and instrument response are taken into account. The synthetic $P$ wave forms for different choices of crack radius are computed for four Scandinavian stations and compared with the initial part of the observed short-period seismogram. The best fit of synthetic and observed seismograms was obtained for a crack radius of 1.5 to $2 \mathrm{~km}$ and a maximum slip of 2.5 to 3 meters.

EMPIRICAL RELATIONS BETWEEN BARRIER INTERVAL AND MAXIMUM SLIP.

Detailed mapping of slip across fault breaks on the surface has been made along the length of the fault for several earthquakes. The distributicn of slip as a function of distance is never a smooth curve with one peak at the center such as expected for a crack without barriers, the case PSV-0, described earlier (Fig. 3. A remarkably smooth slip distribution reported by Matsuda and Yamashina (1974) for the Izu-Hanto-Oki earthquake of 1974 is very much like the case PSV-1 with one barrier. It consists of two peaks with an apparent node in the middle at which a slight change in the strike direction occurs. In most cases, the slip shows several peaks suggesting that an earthquake fault is usually a composite of faults separated by barriers.

A summary of barrier intervals and maximum slip inferred from the observed slip is shown in Table II for earthquakes studied by Matsuda (1972, 1974, 1976), Matsuda and Yamashina (1974), and Tchalenko and Berberian (1975). Representative values for the great Fort Tejon earthquake of 1857 are taken from the description by Wallace (1968, 1973) although the slip distribution along the total fault length is not available for this earthquake.

In order to estimate the barrier interval seismologically, we must calculate synthetic seismograms using the barrier model and compare with the observed data. Bouchon (1978) made such a comparison for the San Fernando earthquake of 1971 as summarized in the preceding section. He also showed that the "composite cracks with unbroken barriers » model is roughly equivalent to the dislocation model with uniform slip such as that used by Aki (1968) and Haskell (1969) for 
the Parkfield earthquake of 1966. From this equivalence, one can make a rough estimate of barrier interval from the rise time such that

$$
\text { barrier interval } \sim \text { rupture velocity - rise time. }
$$

Table I1I summarizes the barrier interval and maximum slip estimated using the above equation from source parameters given by Abe (1974 a, b, 1975) and Kanamori (1972) for four Japanese earthquakes.

As discussed earlier, the corner frequency of small earthquakes may be related to the barrier interval of the fault zone. The observed constant corner frequency of about $1 \mathrm{~Hz}$ for earthquakes in the Stone Canyon area with magnitude $4<M<5$ suggests a barrier interval of $1.5 \mathrm{~km}$ if interpreted by the use of a circular crack model. Assuming that the "highest stress drop " earthquake located at the top of the constant corner frequency path may be modeled by the circular crack (without barriers) of Madariaga (1976), we shall apply the following formulas to this earthquake.

$$
\begin{aligned}
& M=\frac{2 \pi}{3} \mu \Delta U_{\max } a^{2} \\
& f=0.21 \beta / a \\
& \Delta \sigma=\frac{7 \pi}{24} \mu \Delta U_{\max } / a
\end{aligned}
$$

where $M$ is seismic moment, $\mu$ is rigidity, $\Delta U_{\max }$ is the maximum slip, $a$ is the radius of the crack, $\beta$ is shear velocity, $f$ is corner frequency and $\Delta \sigma$ is stress drop. Using the values of seismic moment and corner frequency for the "highest stress drop » earthquake, we find not only its barrier interval, $L=2 a$, but also its maximum slip, $\Delta U_{\max }$.

For the Stone Canyon area, we find that $L=1.5 \mathrm{~km}$ and $\Delta U_{\max }=1 \mathrm{~m}$ corresponding to the top of the constant corner frequency path ( $M 5$ in Fig. 1). The corresponding stress drop is about 400 bars according to equation [5].

In Fig. 13, an arrow is marked on the diagram showing the maximum slip and barrier interval. The end of the arrow corresponds to the "highest stress drop earthquake" in the Stone Canyon area. The arrowhead points to the direction of constant stress drop. We plot, in the same figure, the results obtained by Wallace $(1968,1973)$ for 


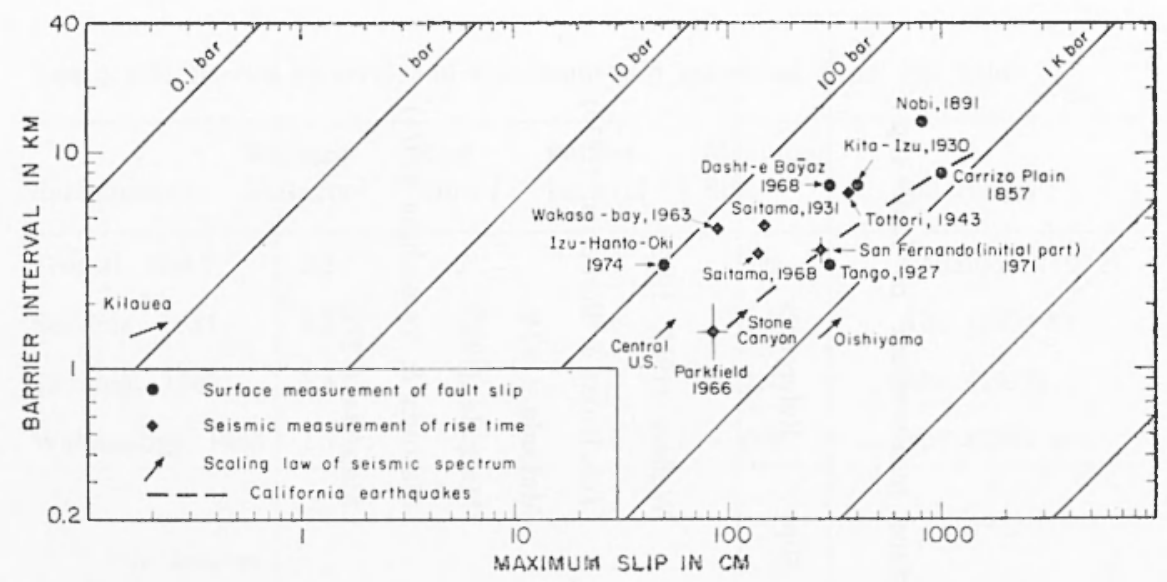

Fig. 13. Relation between the barrier interval and the maximum slip obtained by various methods.

fault breaks of the 1857 earthquake in the Carrizo Plain and by Bouchon (1978) for the initial part of the San Fernando earthquake of 1971. These points appear to lie along the extension of the arrow for the Stone Canyon area, with a slight increase in stress drop for greater earthquakes. Although the data are too scanty to draw any definitive conclusion, they suggest that the barrier interval is not a constant for a fault zone, but increases with the amount of slip involved in an earthquake.

Fig. 13 also shows the results for other areas obtained by geo'ogic and seismic methods as listed in Tables II and III, together with the results from the scaling law data obtained by Chouet et al. (1978). The data points in Fig. 13 are scattered over an area between two lines corresponding to stress drops of 100 and 1000 bars. These values are about an order of magnitude greater than those estimated earlier by the use of crack models without barriers (Aki, 1972; Kanamori and Anderson, 1975). Thus the barrier model can resolve, at least partially, the well known discrepancy between the stress drops measured in the laboratory and those estimated for earthquakes.

The results for Kilauea, although the data are the least complete, show extremely low stress drop, or a long barrier interval for a given maximum slip. This may explain why only scattered evidence of strong ground shaking was observed in the epicentral area of the Island of Hawaii earthquake of November 29, 1975 (Rojahn and Morril, 1977). 
TABLE II. Average barrier interval estimated from surface measurement of fault slip.

\begin{tabular}{|c|c|c|c|c|c|}
\hline Earthquake & Average & Barrier & Interval & Maximum & References \\
\hline $\begin{array}{l}\text { Panorama Hills } \\
\text { Carrizo Plain, } 1857\end{array}$ & & $8 \mathrm{~km}$ & & $11 \mathrm{~m}$ & Wallace $(1968,197 \jmath)$ \\
\hline Dasht-e Bayaz, 1968 & & $7 \mathrm{~km}$ & & $3 \mathrm{~m}$ & Tchalenko \& Berberian (1975) \\
\hline Nobi, 1891 & & $14 \mathrm{~km}$ & & $8 \mathrm{~m}$ & Matsuda (1974) \\
\hline Tango, 1927 & & $3 \mathrm{~km}$ & & $3 \mathrm{~m}$ & Matsuda (1976) \\
\hline I7u-Hanto-Oki, 1974 & & $3 \mathrm{~km}$ & & $0.5 \mathrm{~m}$ & Matsuda \& Yamashina (1974) \\
\hline Kita-Izu, 1930 & & $7 \mathrm{~km}$ & & $4 \mathrm{~m}$ & Matsuda (1972) \\
\hline
\end{tabular}


TABLE III. Barrier interval and maximum slip estimated from rise time.

\begin{tabular}{|c|c|c|c|c|c|}
\hline Earthquake & $\begin{array}{l}\text { Rupture } \\
\text { Velocity } 1\end{array}$ & $\begin{array}{l}\text { Rise } \\
\text { Time : }\end{array}$ & $\begin{array}{l}\text { Barrier } \\
\text { Interval } 3\end{array}$ & $\begin{array}{l}\text { Maximum } \\
\text { Slip }{ }^{4}\end{array}$ & References \\
\hline Tottori, 1943 & 2.3 & 3 & 6.9 & 3.8 & Kanamori (1972) \\
\hline Saitama, 1931 & 2.3 & 2 & 4.6 & 1.5 & Abe $(1974 \mathrm{~b})$ \\
\hline Saitama, 1968 & 3.4 & 1 & 3.4 & 1.4 & Abe (1975) \\
\hline Wakasa-bay, 1963 & 2.3 & 2 & 4.6 & 0.9 & Abe (1974a) \\
\hline
\end{tabular}

1 in $\mathrm{km} / \mathrm{sec}$

2 in sec

3 in $\mathrm{km}$

+ in meters

Prediction OF STRONG MOTION.

With further studies using both geologic and seismic methods, we hope to establish a reliable relation between the barrier interval and the maximum slip for a given seismic region. If this is done, we shall have a powerfull method for calculating the strong motion seismogram for a potential earthquake fault. Among the parameters of an earthquake source needed for calculating the seismogram, the fault length and width may be supplied from maps of geology, seismicity, and plate tectonics. The rupture velocity appears to be roughly a constant. The maximum slip for a fault zone may be estimated from the rate of plate motion and geologic history of slips. Then, the diagram shown in Fig. 13 can supply the final crucial parameter, i. e. the barrier interval, needed for calculating the strong motion seismogram

This approach, at least, offers a framework in which geologic data on past fault breaks and seismological data on small earthquakes can be combined for the purpose of estimating the strong motion of a large earthquake in a given seismic region. 


\section{AckNowledgement.}

We thank Dr. R. E. Wallace of the U. S. Geological Survey and Dr. T. Matsuda of the Earthquake Research Institute, Tokyo University, for providing us with first-hand information and expert opinions on fault breaks observed on the surface. Discussions with Drs. V. I. Keilis-Borok, B. V. Kostrov, R. Madariaga, T. G. Rautian, and P. Richards were helpful in developing the basic idea of the present paper. This work was supported by the National Science Foundation under grant 77-23336 PFR.

\section{REFERENCES}

Alse, K., 1974 a. - Fault parameters determined by near and far - field data: the Wakasa Bay earthquake of March 26, 1963. Bull. Seism. Soc. Am., 64, 1369-1382.

A 3 E K., 1974 b. - Seismic displacement and ground motion near a fault: the Saitama earthquake of September 21, 1931. J. Geophys. Res., 79, 4393-4399.

ABE, K., 1975. - Determination of static and dynamic Jault parameters of the Saitama earlhquake of July 1, 1968. Tectonophysics, 27, 223-238.

AKI, K., 1967. - Scaling law of seismic spectrum. J. Geophys. Res., 72, 1217-1231.

AKI, K., 1968. - Seismic displacement near a Jault. J. Geophys. Res., 73, 5359-5376.

AKI, K., 1972. - Scaling lav of earthquake source time-function. Geophys. J. Roy. Astron. Soc., 31, 3-25.

Акı, К., Сhouet, В., 1975. - Origin of cola waves; source, attenuation and scattering efjects. J. Geophys. Res., 80, 3322-3342.

ANDREWS, D. J., 1976. - Rupture velocity of plane-strain shear cracks. J. Geophys. Res., 81, 5679-5687.

Bouchon, M., 1976. - Discrete wave number representation of seismic wave fields with application to various scattering problems. Ph. D. Thesis, Mass. Inst. of Techn., Cambridge.

Bouchon, M., 1978. - A Dynamic Source model for the San Fernando earlhquake, Bull. Seism. Soc. Am., 68, 1555-1576.

Bouchon, M., AKı, K., 1977. - Discrete wave-number representation of seismicsource wave fields. Bull. Seism. Soc. Am., 67, 259-278. 
Brown, R. D. JR., 1970. - Map showing recently active breaks along the San Andreas and related faults between the Norihern Gabilan range and Cholame Valley, Calif.. Misc. Geol. Invest.. Map I-575, U. S. Geological Survey, Washington D. C..

Burridge, R., 1973. - Admissible speeds for plane-strain self-similar shear cracks with friction but lacking cohesion. Geophys. J. Roy. Astron. Soc., 35, 439-455.

Chouet, В.. Акı, K., Tsujiura, M., 1978. - Regional variation of the scaling law of earthquake source spectra. Bull. Seism. Soc. Am., 68. 49-80.

DAS, S., 1976. - A numerical study of rupture propagation and earthquake source mechanism. Sc. D. Thesis, Mass. Inst. Techn., Cambridge.

D^s, S., AKi, K., 1977 a. A numerical study of two-dimensional spontaneous rupture J. Geophys. Res., 82, 5658-5670.

DAs, S., АкІ, K., 1977 b. Fault plane with barriers: a versatile earthquake model. in Izu Peninsula, Japan. In: The Izu Peninsula, edited by M. Hoshino

Hamano, Y., - Dependence of rupture time history on the heterogeneous distribution of stress and strength on the fault plane, (abstract). EOS, Trans. Am. Geophys. Un., 55, 352.

HASkElL, N. A., 1969. - Elastic displacements in the near-field of a propagating Jault. Bull. Seism. Soc. Am., 59, 865-908.

Johnson, L. R., Mc Evilly, T. V., 1974. - Near-field observations and source parameters of central Calijornia earthquakes. Bull. Seism. Soc. Am., 64, $1855-1886$.

Kanamari, H., 1972. - Determination of efjective tectonic stress associated with earthquake laulting - the Tottori earthquake of 1943. Phys. Earth Planet. Int., 5, 426-434.

Kanamori, H., Anderson, D. L., 1975. - Theoretical basis of some empirical relations in seismology. Bull. Seism. Soc. Am.. 65, 1073-1095.

Madariaga, R., 1976. - The dynamics of an expanding circular fault. Bull. Seism. Soc. Am., 66. 639-666.

MATSUdA, T., 1972. - Surface Jaults associated with Kita-Iza earthquake of 1930 in Izu Peninsula, Japan. In: The Isu Peninsula, edited by M. Hoshino and H. Aoki. Tokai. Univ. Press, Tokyo.

MAtsudA, T., 1974. - Surface Jaults associated with Nobi (Mino-Owari) earthquake of 1891, Japan, Sokuho (in Japanese). Earthq. Res. Inst., Univ. Tokyo, 13, 85-126.

MatsudA, T., 1976. - Active faults and earlhquakes - the geological aspects (in Japanese). 12, 15-32.

Matsuda, T., Yamashina, K., 1974. - Surface faults associated with the Isu-HanioOki earthquake of 1974, Japan. Sokuho (in Japanese). Earthq. Res. Inst., Univ. Tokyo, 14, 135-158. 
Rautian, T. G., Khalturin, V. I., 1976. - Spectral properties of coda of local earthquakes for investigation of source mechanism. Dokladi, Acad. Nauk, USSR, 226, 566-569.

Rojahn, C., Morrill, B. J., 1977. - The Island of Hawaii earthquake of November 29, 1975: strong motion data and damage reconnaissance report. Bull. Seism. Soc. Am., 67, 493-515.

Street, R. L., Herrmann, R. B., Nuttlı, O. W., 1975. - Spectral characteristics of the Lg waves generated by central United States earthquakes. Geophys. J. Roy. Astron. Soc., 41, 51-63.

Tchalenko, J. S., Berberian, M., 1975. - Dashi-e Bayaz Fault, Iran: earthquake and earlier related structures in bedrock. Geol. Soc. Am. Bull., 86, 703-709.

Tsujiurı, M., 1978. - Spectral analysis of the coda waves from local earthquakes. Bull. Earthquake Res. Inst., Tokyo Univ., 53, 1-48.

Wallace, R. E., 1968. - Notes on stream channels offset by the San Andreas fault. southern Coast Ranges, California. Proc. Conf. on Geologic Problems of San Andreas Fault System, Stanford Univ. Publ., Geological Sci., XI, 6-21.

Wallace, R. E., 1973. - Source fracture patterns along the San Andreas fault. Proc. Conf Tectonic Processes of the San Andreas Fault System, ed by R. L. K. Kovach and A. Nur, Stanford Univ. Press, Geological Sci,, XIII, 248-250. 